\title{
Full thickness vs sliced mosaic cartilage graft in tympanoplasty: a comparative study
}

\author{
Mahmoud S. Elfouly ${ }^{1,2}$ (i)
}

\begin{abstract}
Background: Tympanoplasty is one of the most performed procedures in otorhinolaryngology — head and neck surgery. Reconstruction of hearing is one of its targeted goals (Jeffery et al., J Otolaryngol Head Neck Surg 46:48, 2017). Closure of tympanic membrane was accomplished by various grafts. Temporalis fascia is commonly used in tympanoplasty but it could not withstand pressure variations due to its low elasticity (Sözen et al., J Craniofac Surg 23:e280-e283, 2012). Cartilage was preferred in this condition owing to its rigidity (Zhang et al., Otol Neurotol 32: 1234-1238, 2011). However, this rigid character is thought to hinder the acoustic transfer through the cartilage (Bozdemir et al., ORL J Otorhinolaryngol Relat Spec 74:28-32, 2012).

This study was conducted to determine the acoustic characteristics of sliced mosaic cartilage tympanoplasty.

Results: Comparable success rates were found among the 2 groups at 3 months postoperatively; 14 cases (88\%) in group 1 and 20 cases (91\%) in group 2. One year postoperatively, two cases with healed perforation in group 2 showed re-perforation; resulting in decreasing success rate to $81 \%$, in contrast to constant success rate (88\%) in the corresponding follow-up in group 1. However, the difference between the two groups remained insignificant $(P=1$ in both follow ups).
\end{abstract}

Conclusion: Using split thickness cartilage slices arranged in mosaic pattern in type I tympanoplasty successfully overcame the hindering effect of cartilage on acoustic transfer, with no fear regarding take rate or complications.

\section{Background}

Tympanoplasty is one of the most performed procedures in otorhinolaryngology-head and neck surgery. Reconstruction of hearing is one of its targeted goals [1]. Closure of tympanic membrane was accomplished by various grafts. Temporalis fascia is commonly used in tympanoplasty but it could not withstand pressure variations due to its low elasticity [2]. Cartilage was preferred in this condition owing to its rigidity [3]. However, this rigid character is thought to hinder the acoustic transfer through the cartilage [4].

Correspondence: melfouly@gmail.com

'Department of Otorhinolaryngology, Faculty of Medicine, Cairo University, Cairo 11562, Egypt

${ }^{2}$ Kasr Elainy Faculty of Medicine, Cairo University, Kasr Elainy Street, Cairo, Egypt
This study was conducted to determine the acoustic characteristics of sliced mosaic cartilage tympanoplasty.

\section{Methods}

This study was a randomized controlled study, conducted on 38 patients with tympanic membrane perforation presented to Otorhinolaryngology Department, University Hospital, Egypt within the period July 2018 to April 2020.

Inclusion criteria were age 10-60 years old, with dry central perforations for at least 3 months of any size and any site whether due to otitis media, failure of healing after trauma or ventilation tube removal in addition to air-bone gap $(\mathrm{ABG}) \leq 30 \mathrm{~dB}$. Any patient with perforation due to cholesteatoma, mastoid surgery, previous tympanoplasty, any cause of delayed healing as anemia,

\section{SpringerOpen}

(c) The Author(s). 2021 Open Access This article is licensed under a Creative Commons Attribution 4.0 International License, which permits use, sharing, adaptation, distribution and reproduction in any medium or format, as long as you give appropriate credit to the original author(s) and the source, provide a link to the Creative Commons licence, and indicate if changes were made. The images or other third party material in this article are included in the article's Creative Commons licence, unless indicated otherwise in a credit line to the material. If material is not included in the article's Creative Commons licence and your intended use is not permitted by statutory regulation or exceeds the permitted use, you will need to obtain permission directly from the copyright holder. To view a copy of this licence, visit http://creativecommons.org/licenses/by/4.0/. 
granulomatosis, malignancy, etc., age $<10$ or $>60$ years old, or unfit for surgery was excluded from this study.

Patients were divided into two groups randomly: group 1 included 16 patients who underwent underlay full thickness cartilage tympanoplasty.

Group 2 included 22 patients who underwent underlay sliced cartilage tympanoplasty. In all cases, the cartilage graft was used in mosaic technique.

Preoperatively, all patients were subjected to history taking and clinical assessment by otoendoscopy for the size and site of perforation, and hearing assessment by pure tone audiometry.

All patients had surgery under general anesthesia. The tragal cartilage was harvested in all cases. After infiltration of local xylocaine and adrenaline, incision of medial aspect on cartilage was done and the cartilage was dissected from the skin and soft tissue using scissor. The most lateral part of cartilage was left for cosmetic purposes. The perichondrium was dissected from both sides.

The cartilage was handled according to the technique of each group. It was left as such of its thickness $(1 \mathrm{~mm})$ in group 1 while in group 2 it was sliced into thickness around $0.5 \mathrm{~mm}$ (Fig. 1).

The middle ear was approached either through postauricular or transcanal approach. Tympanoplasty was done endoscopically or microscopically.

The edges of the perforation were trimmed using an angled pick (Fig. 2). In cases with large perforation with not enough rim of drum remnant, suspension of cartilage on osseous annular was done. The middle ear is packed with gel foam. The cartilage was placed in an underlay fashion (Fig. 3), using mosaic pattern in which slices (or pieces) of cartilage, are pieced together, like the pieces of a jigsaw puzzle (Figs. 4 and 5).

Postoperatively, the patients were discharged in the same day on medical treatment of antibiotic and analgesic

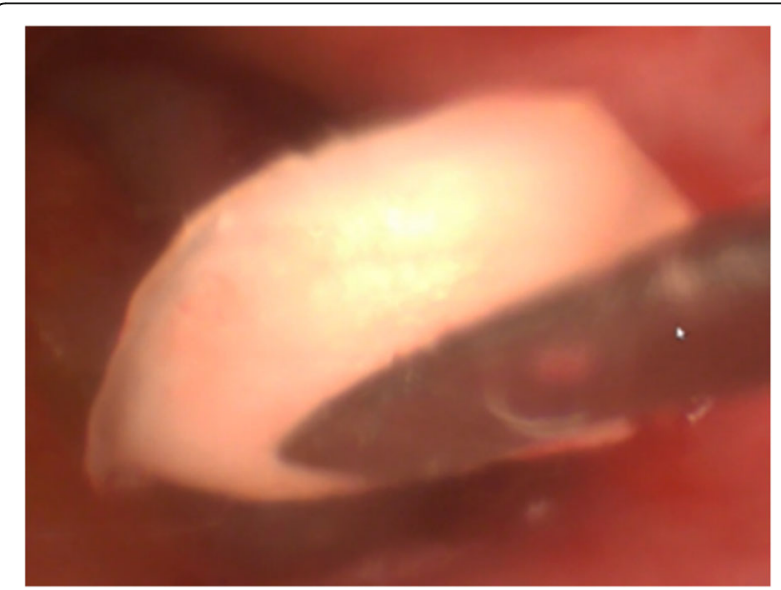

Fig. 1 Sliced cartilage

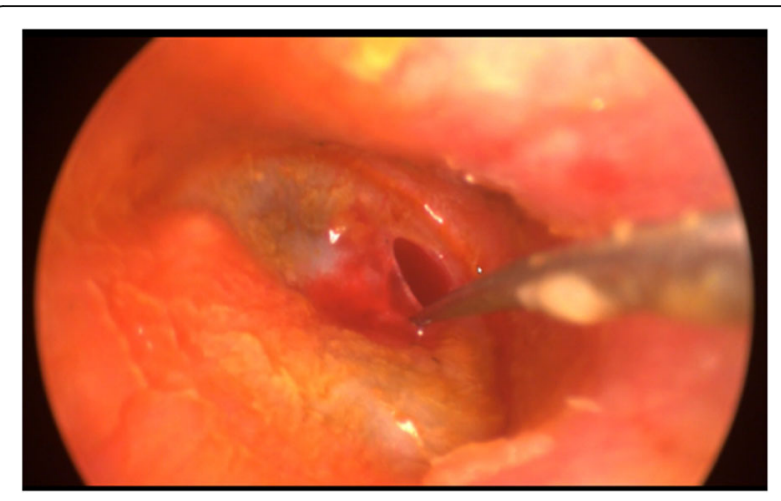

Fig. 2 Trimming of cartilage

for 5 days. The bandage or ear pack was removed after 5 days and the stitches were removed. Then, the patients were advised to use local ear drops for 3 days.

The patients of all groups were assessed at intervals of 3 and 12 months, using subjective improvement, endoscopic examination, and audiometry. The results were analyzed regarding graft take, audiological gain, and complication. The success take is defined as graft take without residual perforation, lateralization or medialization. Audiological gain is defined as the difference in mean ABG before and after surgery at frequencies of 500, 1000, and $2000 \mathrm{~Hz}$.

Data were coded and entered using the statistical package for the Social Sciences (SPSS) version 26 (IBM Corp., Armonk, NY, USA). Data was summarized using mean, standard deviation (SD), median (med.), minimum (min.), and maximum (max.) in quantitative data and using frequency (count) and relative frequency (percentage) for categorical data. Comparisons between quantitative variables were done using the non-parametric Mann-Whitney test (Chan, 2003a). For comparing categorical data; chi square $\left(\chi^{2}\right)$ test was performed.

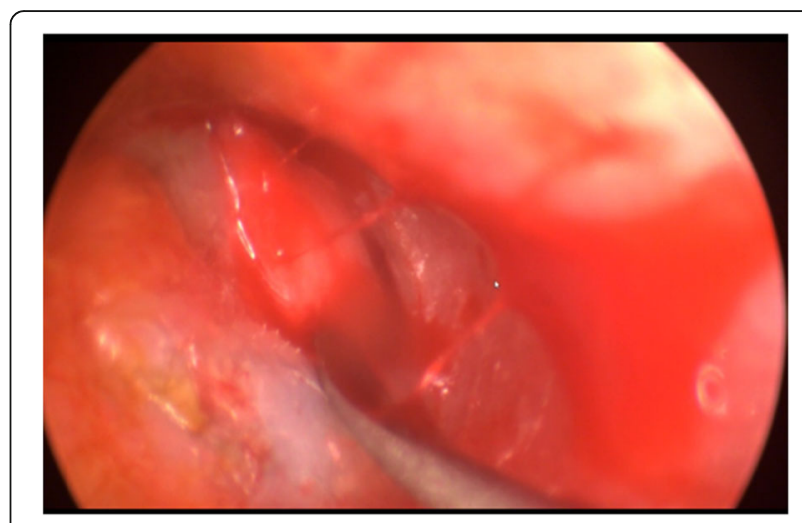

Fig. 3 Placing the cartilage in underlay fashion 


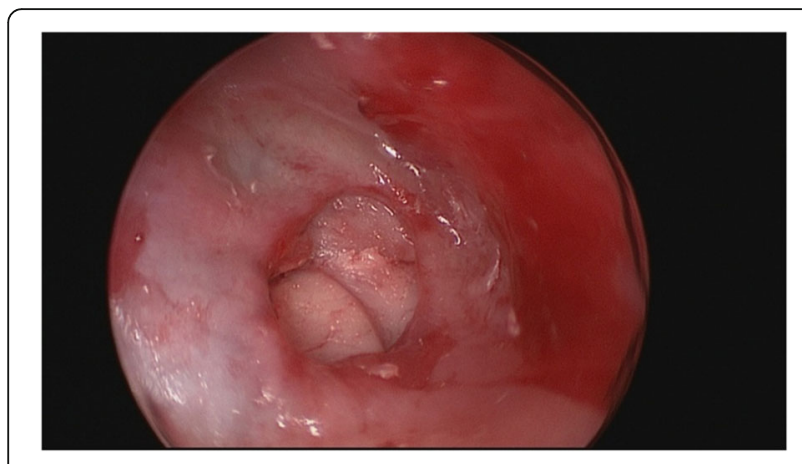

Fig. 4 Full thickness mosaic technique, right ear

Exact test was used instead when the expected frequency is less than 5 (Chan, 2003b). $P$ values less than 0.05 were considered as statistically significant.

\section{Results}

Demographic data and preoperative characteristics of the perforations

This study included 38 patients, with age range 11-49; 20 males and 18 females. Most of perforations in this study were due to infection (Table 1 ).

\section{Operative data}

Transcanal approach was used in 32 cases, while postauricular approach was used in 6 cases. The procedure was done under endoscopic assistance in 28 cases and microscopic assistance in 10 cases (Table 2).

\section{Postoperative healing results}

Comparable success rates were found among the 2 groups at 3 months postoperatively; 14 cases (88\%) in group 1 and 20 cases (91\%) in group2. One year postoperatively, two cases with healed perforation in group 2 showed re-perforation; resulting in decreasing success

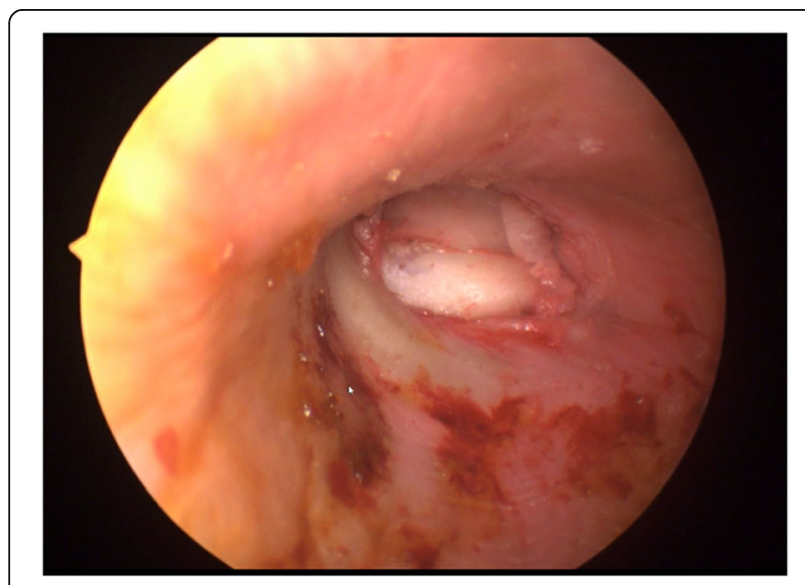

Fig. 5 Partial thickness mosaic cartilage tympanoplasty, left ear
Table 1 The distribution of cases, their demographic date, and the cause and the preoperative characteristics of their perforations

\begin{tabular}{lll}
\hline & $\begin{array}{l}\text { Group 1 } \\
\text { (full thickness) }\end{array}$ & $\begin{array}{l}\text { Group 2 } \\
\text { (partial thickness) }\end{array}$ \\
\hline Total numbers of cases & 16 & 22 \\
Age range & $23-42$ & $11-49$ \\
Sex & 10 & 10 \\
$\quad$ Male & 6 & 12 \\
$\quad$ Female & & \\
Cause of perforation & 14 & 18 \\
Infection & 2 & 4 \\
$\quad$ Trauma & & \\
Site of perforation & 2 & 4 \\
Anterior & 12 & 16 \\
Center & 2 & 2 \\
Posterior & & \\
Size of perforation & 4 & 4 \\
Small & 8 & 6 \\
Medium & 4 & 12 \\
large & &
\end{tabular}

rate to $81 \%$, in contrast to constant success rate $(88 \%)$ in the corresponding follow-up in group 1 . However, the difference between the 2 groups remained insignificant ( $P=1$ in both follow-ups).

\section{Postoperative hearing results}

Preoperatively, there was no statistically significant difference in ABG between the 2 groups. At 3 months postoperatively, the $\mathrm{ABG}$ declined to $11 \pm 3 \mathrm{SD} \mathrm{dB}$ in group 2 which was significantly less than group $1(P=$ $0.03)$, in which the $\mathrm{ABG}$ was $15 \pm 4 \mathrm{SD} \mathrm{dB}$ at this time of follow-up. Although, at 1 year postoperatively, the difference of the ABG was in favor of group $2(10 \pm 3 \mathrm{SD}$ $\mathrm{dB}$ in group 2 versus $13 \pm 4 \mathrm{SD} \mathrm{dB}$ in group 1 ), it was not statistically significant (Table 3 ).

\section{Postoperative complications}

Infection was reported in only two cases in group 2 during the whole period of the follow-up.

Table 2 The approaches used in the cases of the 2 groups

\begin{tabular}{lll}
\hline & Group 1 & Group 2 \\
\hline Approach & 12 & 20 \\
Transcanal & 4 & 2 \\
Postauricular & & \\
Assistance & 12 & 16 \\
Endoscopic & 4 & 6 \\
Microscopic & 4 \\
\hline
\end{tabular}


Table 3 The values of preoperative and postoperative ABG (in $\mathrm{dB}$ ) in both groups

\begin{tabular}{|c|c|c|c|c|c|c|c|c|c|}
\hline & \multicolumn{4}{|c|}{ Group1 } & \multicolumn{4}{|c|}{ Group2 } & \multirow[t]{2}{*}{$P$ value } \\
\hline & Mean & SD & Minimum & Maximum & Mean & SD & Minimum & Maximum & \\
\hline Preoperative ABG & 23 & 5 & 13 & 29 & 24 & 5 & 13 & 30 & 0.8 \\
\hline Postoperative ABG (3 months) & 15 & 4 & 9 & 19 & 11 & 3 & 6 & 15 & 0.03 \\
\hline Postoperative ABG (1 year) & 13 & 4 & 6 & 19 & 10 & 3 & 5 & 14 & 0.07 \\
\hline
\end{tabular}

\section{Discussion}

Although tympanoplasty using cartilage grafts has better graft take than temporalis fascia graft, its rigid quality lead to worse hearing outcomes [4]. It has been thought that the cartilage of greater thickness yield worse hearing outcome [5].

Slicing of the cartilage was one of the solutions proposed by researchers to improve the hearing outcomes. Overbosch, 1971, was the first one who proposed such suggestion. The concept of slicing the cartilage to improve acoustic gain is based on the principle of mass and stiffness of the cartilage [6]. This suggestion was supported by the results of the laboratory studies of Zanhert et al. and Lee et al., as well as the clinical studies done by Khan and Parab, Mokbel et al., and Nemade et al. [7-11].

In addition to slicing of cartilage to help in reducing acoustic transfer loss with the cartilage, modification of graft insertion technique is another suggestion. Surgical processing of the cartilage in terms of its shape and location can alter its acoustic transfer properties [12]. This idea was supported by the studies of Murbe et al. and Arora et al. in which they found favorable acoustic results with arranging the cartilage in palisade manner. The concept of arranging the cartilage in palisades is that manner facilitates mobility of the cartilage and improves the acoustic impedance [13, 14]. The same concept was adopted and supported by Abou Mayaleh et al., but they used mosaic technique in which pieces of cartilage are grouped together in jigsaw manner like the leaves of a tulip flower [15]. This mosaic technique is the one adopted in this current study but with using cartilage pieces of various sizes and shapes as Dornhoffer did in his work [16].

This current study supported the combined acoustic benefit of both sliced cartilage and mosaic technique as well. The postoperative decline in ABG after 3 months was found to be significantly better when partial thickness cartilage was used compared to full thickness one. The mean audiological gain in the first 3 months postoperatively in partial thickness group was $13 \mathrm{~dB}$ compared to $8 \mathrm{~dB}$ in the other group with significant $P$ value (0.03). Therefore, according to the results of this 3-month follow-up, it could be said the sliced cartilage has a better acoustic benefit. The 1-year follow-up showed that acoustic results of full thickness group were found comparable to the corresponding results in sliced group. The audiological gain in sliced group was better but not significant statistically $(P=0.07)$. The latter results could be explained by the documented phenomenon of dissolution of cartilage with time [17-19]. In the current study, it could be assumed that the dissolution of cartilage along time has changed the vibratory property of the cartilage which added to acoustic benefit of mosaic technique which yielded finally to comparable results to the sliced cartilage.

Another great advantage of using such technique could be achieved in persistent tubal dysfunction. In such condition, suspension of cartilage on osseous annular is necessary to achieve strong stability. Suspension of cartilage on osseous annular is associated with more transfer loss unlike to suspension on tympanic membrane remnants. This is because the latter technique of suspension relies on the stiffness of normal tympanic membrane. Therefore, in chronic tubal obstruction, using mosaic technique together with slicing the cartilage could eliminate the feared effect of suspension of cartilage on the osseous annular [13]. Moreover, it could be the protocol in all cases, as there is consensus that tubal function could not be reliably predicted preoperatively [8].

Tragal cartilage was the one that was used in all cases in this current study. Moreover, many other authors used it owing to its advantages in being accessible, thin, flat and in adequate quantity for reconstruction the entire tympanic membrane [20]. It is worth mentioning that the acoustic properties of the conchal cartilage are the same as that of the tragal cartilage [13].

This study had some limitations. The number of cases was limited to some extent. The duration of follow-up was relatively short. Using of blade in slicing was not so precise compared to the slicer.

The authors suggest in the future studies further study of using of sliced cartilage in myringoplasty on a larger sample of population and for longer time of follow-up.

\section{Conclusion}

Using split thickness cartilage slices arranged in mosaic pattern in type I tympanoplasty successfully overcame the hindering effect of cartilage on acoustic transfer, with no fear regarding take rate or complications. 


\section{Abbreviations}

ABG: Air-bone gap; DB: Decibel

\section{Acknowledgements}

Not applicable.

\section{Author's contributions}

The author declares that he is the single author of this manuscript. The author read and approved the final manuscript.

\section{Funding}

This research is entirely funded by Kasr Elainy Hospital.

\section{Availability of data and materials}

The datasets used and/or analyzed during the current study are available from the corresponding author on reasonable request.

\section{Declarations}

\section{Ethics approval and consent to participate}

This study is approved by the ethical committee of Kasr Elainy College of medicine, Cairo University with no available reference number.

All patients gave their written informed consent to undergo surgery and participate in this study, and if the patient is under 16 years old, a written informed consent was obtained from the legal guardian of the patient.

\section{Consent for publication}

All the participants in this study gave their written informed consent or from their legal guardian if under 16 years old for the publication of this study.

\section{Competing interests}

The author declares no competing interests.

Received: 11 March 2021 Accepted: 15 April 2021

Published online: 02 July 2021

\section{References}

1. Jeffery CC, Shillington C, Andrews C, Ho A (2017) The palisade cartilage tympanoplasty technique: a systematic review and meta-analysis. J Otolaryngol Head Neck Surg 46(1):48

2. Sözen E, Uçal YO, Tansuker HD, Coskun BU, Korkut AY, Dadas B (2012) Is the tragal cartilage necessary for type 1 tympanoplasties? J Craniofac Surg 23(4): e280-e283

3. Zhang ZG, Huang QH, Zheng YQ, Sun W, Chen YB, Si Y (2011) Three autologous substitutes for myringoplasty: a comparative study. Otol Neurotol 32(8):1234-1238

4. Bozdemir K, Kutluhan A, Yalçıner G, Tarlak B, Bilgen AS (2012) Tympanoplasty with island cartilage or temporalis fascia: a comparative study. ORL J Otorhinolaryngol Relat Spec 74(1):28-32

5. Yang T, Wu X, Peng X, Zhang Y, Xie S, Sun H (2016) Comparison of cartilage graft and fascia in type 1 tympanoplasty: systematic review and metaanalysis. Acta Otolaryngol 136(11):1085-1090

6. Overbosch HC (1971) Homograft myringoplasty with micro-sliced septal cartilage. Pract Otorhinolaryngol 33(5):356

7. Zahnert T, Hüttenbrink KB, Mürbe D, Bornitz M (2000) Experimental investigations of the use of cartilage in tympanic membrane reconstruction. Otol Neurotol 21(3):322-328

8. Lee CF, Chen JH, Chou YF, Hsu LP, Chen PR, Liu TC (2007) Optimal graft thickness for different sizes of tympanic membrane perforation in cartilage myringoplasty: a finite element analysis. Laryngoscope 117(4):725-730

9. Khan MM, Parab SR (2015) Comparative study of sliced tragal cartilage and temporalis fascia in type I tympanoplasty. J Laryngol Otol 129(1):16

10. Mokbel KM, Thabet ESM (2013) Repair of subtotal tympanic membrane perforation by ultrathin cartilage shield: evaluation of take rate and hearing result. Eur Arch Otorhinolaryngol 270(1):33-36

11. Nemade SV, Dabholkar JP (2014) Healing and hearing results of temporalis fascia graft Vs cartilage graft (Full thickness and half thickness) in type I tympanoplasty. Online J Otolaryngol 4(3):11-13

12. Williams KR, Blayney AW, Lesser THJ (1997) Mode shapes of a damaged and repaired tympanic membrane as analysed by the finite element method. Clin Otolaryngol Allied Sci 22(2):126-131
13. Mürbe D, Zahnert T, Bornitz M, Hüttenbrink KB (2002) Acoustic properties of different cartilage reconstruction techniques of the tympanic membrane. Laryngoscope 112(10):1769-1776

14. Arora N, Passey JC, Agarwal AK, Bansal R (2017) Type 1 tympanoplasty by cartilage palisade and temporalis fascia technique: a comparison. Indian J Otolaryngol Head Neck Surg 69(3):380-384

15. Abou HM, Heshiki R, Portmann D, Négrevergne M (2005) Reinforcing tympanoplasty with cartilage mosaic (differences from the palisade technique). Rev Laryngol Otol Rhinol 126(3):181-189

16. Dornhoffer JL (2003) Cartilage tympanoplasty: indications, techniques, and outcomes in A 1,000-patient series. Laryngoscope 113(11):1844-1856

17. Dornhoffer $J \mathrm{~L}$ (2006) Cartilage tympanoplasty. Otolaryngol Clin North Am 39(6):1161-1176

18. Duckert LG, Müller J, Makielski KH, Helms J (1995) Composite autograft "shield" reconstruction of remnant tympanic membranes. Am J Otol 16(1): 21-26

19. Yung M (2008) Cartilage tympanoplasty: literature review. J Laryngol Otol 122(7):663

20. Parelkar K, Thorawade V, Marfatia H, Shere D (2020) Endoscopic cartilage tympanoplasty: full thickness and partial thickness tragal graft. Braz J Otorhinolaryngol 86(3):308-314

\section{Publisher's Note}

Springer Nature remains neutral with regard to jurisdictional claims in published maps and institutional affiliations.

\section{Submit your manuscript to a SpringerOpen ${ }^{\circ}$ journal and benefit from:}

- Convenient online submission

- Rigorous peer review

- Open access: articles freely available online

- High visibility within the field

- Retaining the copyright to your article

Submit your next manuscript at $\boldsymbol{\nabla}$ springeropen.com 